Louisiana State University

LSU Digital Commons

Faculty Publications

Department of Biological Sciences

2-24-2011

\title{
LEA proteins during water stress: Not just for plants anymore
}

\author{
Steven C. Hand \\ Louisiana State University \\ Michael A. Menze \\ Louisiana State University \\ Mehmet Toner \\ Massachusetts General Hospital \\ Leaf Boswell \\ Louisiana State University \\ Daniel Moore \\ Louisiana State University
}

Follow this and additional works at: https://digitalcommons.Isu.edu/biosci_pubs

\section{Recommended Citation}

Hand, S., Menze, M., Toner, M., Boswell, L., \& Moore, D. (2011). LEA proteins during water stress: Not just for plants anymore. Annual Review of Physiology, 73, 115-134. https://doi.org/10.1146/annurev-

physiol-012110-142203

This Article is brought to you for free and open access by the Department of Biological Sciences at LSU Digital Commons. It has been accepted for inclusion in Faculty Publications by an authorized administrator of LSU Digital Commons. For more information, please contact ir@lsu.edu. 


\section{Eastern Illinois University}

\section{The Keep}

Faculty Research \& Creative Activity

Biological Sciences

January 2011

\section{LEA Proteins during Water Stress: Not Just for Plants Anymore}

Steven C. Hand

Louisiana State University

Michael A. Menze

Eastern Illinois University, michael.menze@louisville.edu

Mehmet Toner

Harvard Medical School

Leaf Boswell

Louisiana State University

Daniel Moore

Louisiana State University

Follow this and additional works at: http://thekeep.eiu.edu/bio_fac

Part of the Biology Commons

\section{Recommended Citation}

Hand, Steven C.; Menze, Michael A.; Toner, Mehmet; Boswell, Leaf; and Moore, Daniel, "LEA Proteins during Water Stress: Not Just for Plants Anymore" (2011). Faculty Research \& Creative Activity. 53.

http://thekeep.eiu.edu/bio_fac/53 


\section{LEA Proteins during Water Stress: Not Just for Plants Anymore}

Steven C. Hand ${ }^{\mathrm{a}, 1}$, Michael A. Menze ${ }^{\mathrm{a}}$, Mehmet Toner ${ }^{\mathrm{b}}$, Leaf Boswell ${ }^{\mathrm{a}}$ and Daniel Moore ${ }^{\mathrm{a}}$

${ }^{\mathrm{a}}$ Division of Cellular, Developmental and Integrative Biology, Department of Biological Sciences, Louisiana State University, Baton Rouge, LA 70803 USA and

${ }^{\mathrm{b}}$ Center for Engineering in Medicine and Surgical Services, Massachusetts General Hospital, Harvard Medical School and Shriners Hospitals for Children, 51 Blossom Street, Boston, MA 02114, USA

${ }^{1}$ To whom correspondence should be addressed: shand@LSU.edu Keywords: desiccation tolerance, anhydrobiosis, osmolytes, trehalose, intrinsically disordered proteins.

Running title: Late Embryogenesis Abundant Proteins in Animals. 


\section{Article Table of Contents}

Abbreviations and Key Definitions

Abstract

Introduction

Distribution and Expression of LEA Proteins in Animals

Subcellular Targeting of LEA Proteins

Structure of LEA Proteins in Hydrated and Dry States

Hydrophilic Nature and Random Coil in Aqueous Solution

Increase in Secondary Structure during Drying

Structural Stability and Intra-protein Hydrogen Bonding Increases during Desiccation

Physiological Roles of LEA Proteins with and without Sugars

Protection of Proteins and Organelles

Interactions with Membranes

Stabilization of Sugar Glasses

Hydration Buffers and Ion Sequestration

Summary Remarks and Future Issues

Disclosure Statement

Acknowledgments

Literature Cited

Table

Figure Legends

Figures 


\section{Abbreviations and Key Definitions}

\section{Abbreviations:}

1. $\mathrm{RH}$ - relative humidity

2. DJ - dauer juvenile

3. LDH - lactate dehydrogenase

4. CS - citrate synthase

5. EST - expressed sequence tag

6. BLAST - basic local assignment search tool

7. POPP - protein or oligonucleotide probability profile

8. $T_{\mathrm{m}}$ - gel-to-liquid crystalline phase-transition temperature

9. $T_{\mathrm{g}}$ - glass transition temperature

\section{Key Definitions:}

1. Anhydrobiosis: life without water, i.e., the ability of to survive severe desiccation

2. Vitrification: the transition of a substance into an amorphous glass state, in which rates of molecular diffusion are greatly reduced

3. Compatible Osmolyte: intracellular organic solute that helps maintain osmotic balance and cell volume, and whose presence does not perturb macromolecular structure/function

4. Intrinsically Disordered Protein: a protein that lacks well-defined, three-dimensional structure in aqueous solution

5. Hydration Buffer: the concept that unstructured proteins bind large numbers of water molecules, which can be released inside cells during dehydration to provide beneficial protection

6. Hydrophilic: water loving, i.e., the strong propensity of a certain molecules to interact with water by hydrogen bonding

7. Amphipathic: a molecule that contains both polar (hydrophilic) and non-polar (hydrophobic) regions 


\begin{abstract}
Late embryogenesis abundant (LEA) proteins are extremely hydrophilic proteins that were first identified in land plants. Intracellular accumulation is tightly correlated with acquisition of desiccation tolerance, and data support their capacity to stabilize other proteins and membranes during drying, especially in the presence of sugars like trehalose. Exciting reports now show LEA proteins are not restricted to plants; multiple forms are expressed in desiccationtolerant animals from at least four phyla. We evaluate here the expression, subcellular localization, biochemical properties and potential functions of LEA proteins in animal species during water stress. LEA proteins are intrinsically unstructured in aqueous solution, but surprisingly, many only assume their native conformation during drying. They are targeted to multiple cellular locations, including mitochondria, and evidence supports that LEA proteins stabilize vitrified sugar glasses thought to be important in the dried state. More in vivo experimentation will be necessary to fully unravel the multiple functional properties of these macromolecules during water stress.
\end{abstract}




\section{INTRODUCTION}

Deficit in cellular water is a pervasive issue confronting both aquatic and terrestrial organisms. Subfreezing temperatures, desiccating conditions in xeric climates, and the osmotic variation seen in aqueous habitats are common environmental conditions that can impose severe water stress and a threat to life $(1,2)$. It is well established that many organisms facing water stress possess systems of compatible osmolytes, i.e., low molecular weight solutes accumulated in the intracellular compartment for osmotic balance. Other organic solutes like the sugar trehalose can actually stabilize biological structures during water stress (3-6). Drying because of evaporative water loss is the most common mechanism for dehydration, although during winter in northern temperate regions freezing can also occur, which reduces the liquid water in extracellular fluids and can lead to intracellular dehydration in multicellular organisms and the concomitant increase in intracellular solutes. However, it has become apparent that small organic solutes are not the only components that contribute to an organism's desiccation tolerance. Protective macromolecules also are correlated with desiccation resistance and are of several types, but include Late Embryogenesis Abundant (LEA) proteins, small stress proteins like Artemia P26, Hsp 21 and Hsp 22 (7-16), and anhydrin (17). Both LEA proteins and anhydrin are examples of the extensive group of intrinsically disordered proteins (18)

LEA proteins were first identified in land plants $(19,20)$, and their expression is associated with desiccation tolerance in seeds and anhydrobiotic plants (21). As the name suggests, these proteins were originally discovered in late stages of embryo development in plant seeds (19). Over the last several years, a series of remarkable findings have shown these proteins to be present in at least four animal phyla. In this review, we will focus primarily on the expression, cellular localization, biochemical properties and potential functions of LEA proteins 
in animal species. For broader reviews covering LEA proteins in non-animal species, a number of useful reviews are available (22-25).

\section{DISTRIBUTION AND EXPRESSION OF LEA PROTEINS IN ANIMALS}

LEA proteins are not viewed as being restricted to plants anymore, now having been documented in bacteria (26-28), cyanobacteria (29), slime molds (30), and fungi (31-33). In addition a steady increase in reports of LEA-like protein in animals has been observed in the last several years. Over 30 protein sequences for LEA and LEA-like proteins (Table 1) can be found in the National Center for Biotechnology Information (NCBI) data base. Animals for which LEA-like proteins have been reported are nematodes (17, 34-38), rotifers (39-41), embryos of the brine shrimp Artemia franciscana (42-45), collembolan species including the arctic springtail Megaphorura arctica $(46,47)$, the chironomid larva Polypedilum vanderplanki (48), and tardigrades (as referenced to an EST library, (49)).

Bioinformatics tools such as the BLAST algorithm demonstrate relatedness among LEA proteins, which is partly limited due to protein regions of low sequence complexity. Novel computational methods such as POPP analysis (Protein or Oligonucleotide Probability Profile) may offer new insights in the relatedness of LEA protein sequences (50). As more LEA-related sequences are discovered in animals, the traditional BLAST algorithm may continue to offer basic insight into the relatedness of LEA-like proteins in animals. New classifications of groups will most likely evolve with the development of new bioinformatics tools and the increase in available sequence data.

Two related but divergent LEA-like genes (Arlea1A, ArlealB) located on two separate chromosomes are described in the bdelloid rotifer Adineta ricciae (51). Expression of both 
genes increases several-fold during desiccation. Interestingly, the protein sequences of both genes are similar but their structure in the hydrated state differs substantially. ArLEA1A is largely unstructured in the hydrated state and assumes $\alpha$-helical structure upon drying. ArLEA1B, in contrast, is predominately $\alpha$-helical in the hydrated state. Furthermore, ArLEA1A prevents desiccation-induced aggregation of citrate synthase whereas ArLEA1B increases the aggregation of this enzyme and likely interacts preferably with phospholipid membranes (51). The hydropathy score for both proteins is -0.46 , which is moderately hydrophilic (e.g. BSA = 0.43). LEA proteins are in general highly hydrophilic. The average hydropathy score for 30 group 3 LEA proteins from plants is $-0.97 \pm 0.3(51,52)$, and most LEA and LEA-like proteins from animals score below -1 (Table 1). A homolog for ArLEA1B is reported for the closely related rotifer A. vaga (lea-1B'). This species also expresses a protein with a very similar sequence to lea-1B' that has a deletion of 123 amino acids (lea1C). The longer proteins ArLEA1A, ArLEA1B, and lea-1B' have high sequence similarities to the Dauer Up-Regulated family member (Dur-1) protein from Caenorhabditis elegans (NP_001023145.1) with e-values between $6 \mathrm{e}^{-8}$ and $1 \mathrm{e}^{-12}$.

Browne et al. reported in 2002 the desiccation-induced expression of a group-3 LEA protein in the nematode Aphelenchus avenae. This protein is composed of 143 amino acids, is highly hydrophilic (hydropathy score: -1.585 ), and exhibits in its primary structure 4 copies of a 11-mer motif that is characteristic of group-3 LEA proteins (34). Sequence fragments for a different nematode species was reported earlier by Solomon et al. (2000) and annotated at that time as a LEA-like protein. Two other deduced sequences from A. avenae that are designated as LEA-like proteins can be found at NCBI (Table 1). 
At least five different LEA-like proteins are reported in the desiccation tolerant embryo of the brine shrimp A. franciscana (42-44). The first three are designated as group 3 proteins (Table 1). AfrLEA1 is highly hydrophilic and exhibits sequence similarity with a $C$. elegans LEA-like protein (CeLEA-1; 2 $\mathrm{e}^{-12}$ ). AfrLEA2 exhibits homology to group 3 plant LEA proteins (e.g. Brassica napus, P13934.2, 2 $\mathrm{e}^{-5}$ ). The mitochondrial localized protein AfrLEA3m shows high similarities to both the nematode protein CeLEA-1 $\left(8 \mathrm{e}^{-7}\right)$ as well as a LEA-like protein from the thale cress Arabidopsis thaliana $\left(8 \mathrm{e}^{-7}\right)$. The two group 1 LEA proteins (43); Table 1) belong to the LEA_5 superfamily (pfam00477) and are the only representatives of LEA group 1 proteins in animals for which sequence data are available. These group 1 proteins from A. franciscana are virtually identical except for a mitochondrial targeting sequence and are highly similar to the EM1-protein from A. thaliana $\left(2 \mathrm{e}^{-25}\right)$.

Expression levels for the mRNA of the group 3 LEA proteins from A. franciscana are shown in Figure 1. Each developmental stage with the capacity for anhydrobiosis (diapause and post-diapause embryos) expresses high levels of message compared to the desiccation-intolerant larval stage $(42,44)$. Specifically, mRNA levels for the two cytoplasmic LEA proteins, Afrleal and Afrlea2, are 7-fold and 14-fold higher in the desiccation-tolerant stages compared to the intolerant stage, and similarly, mRNA for the mitochondrial Afrlea3m is elevated 9-fold and 11fold (Fig. 1). This differential expression is consistent with a role for these gene products in survivorship during dehydration. Similarly, Sharon et al. (43) reports expression of two mRNAs encoding for group 1 LEA proteins in post-diapause embryos of A. franciscana but found no expression in larval stages. These results were generally confirmed by Chen et al. (45).

For the marine rotifer Brachionus plicatilis three EST transcripts matching group 3 LEA proteins are reported in (40), and two LEA-like protein sequences (BpaLEA-1 and BpaLEA-2) 
are available in the protein database of NCBI (Table 1). Both proteins are highly hydrophilic but differ substantially in size by about 360 amino acids. BpaLEA-1 shows high similarities to CeLEA-1 from C. elegans $\left(>8 \mathrm{e}^{-20}\right)$ and to a group 3 LEA protein from the soybean, Glycine max. BpaLEA-2 exhibits high resemblance to a LEA-domain containing protein from A. thaliana $\left(\mathrm{NP} \_193834.11, \mathrm{e}^{-11}\right)$.

Multiple nematode species have been reported to possess LEA proteins. Hydropathy values for these proteins are generally below -1. Two LEA-like proteins are described in $C$. elegans (38) and the closely related species Caenorhabditis briggsae (Table 1). Ce-LEA1 RNA expression increases about 20 -fold after $8 \mathrm{~h}$ of moderate desiccation stress in dauer juveniles (DJ) of $C$. elegans. Furthermore, reduction in Ce-LEA1 expression by RNAi-mediated gene silencing significantly reduces survival of DJ after several stresses such as desiccation, heat shock and osmotic shock (38). CBR-LEA1, the Ce-LEA1 homolog in C. briggsae, shows high homology to a LEA3-like protein from $P$. vanderplanki $\left(3 \mathrm{e}^{-17}\right)$. Two LEA-like EST sequences are described for the peanut pod nematode Ditylenchus. africanus (37) and one for the meadow nematode Pratylenchus penetrans. The EST's show similarities to LEA-like proteins from $P$. vanderplanki, Steinernema carpocapsae, and C. elegans, but no experimental evidence on function or expression currently exists. Steinernema feltiae and S. carpocapsae are entomopathogenic nematodes and can be described as slow-dehydration strategists. Infective juveniles (IJ) of $S$. feltiae accumulate a LEA-like protein about 10-fold above control when exposed to $97 \%$ relative humidity (RH) for 3 days (53), and message for another LEA-like protein (Sf-LEA-1) was increased over 100-fold after exposure to $97 \% \mathrm{RH}$ for $24 \mathrm{~h}$ (36). The message for several LEAlike proteins was also found to increase in response to desiccation and osmotic shock in the closely related species $S$. carpocapsae (35). An EST sequence encoding for a protein with 
homology to the nematode LEA-like protein CeLEA1 $\left(6 \mathrm{e}^{-4}\right)$ is expressed in the arctic springtail (Onychiurus arcticus) (47), and desiccation-induced proteins that cross react with an antiserum against ArLEA1A are described for several soil and surface dwelling Collembola (46). Three different LEA-like proteins are upregulated in final instar larvae of the anhydrobiotic chironomid P. vanderplanki in response to desiccation and osmotic stress (48). PvLEA1 and PvLEA3 exhibit high homologies to the $C$. elegans LEA-like protein Ce-LEA1 $\left(9 \mathrm{e}^{-32}\right.$ and $\left.3 \mathrm{e}^{-13}\right)$, whereas PvLEA2 exhibits higher homology to a LEA-domain containing protein from A. thaliana $\left(1 \mathrm{e}^{-05}\right)$.

\section{SUBCELLULAR TARGETING OF LEA PROTEINS}

As can be gleaned from the preceding overview of LEA distributions in animals, multiple LEA proteins are found frequently within a single organism. Such a pattern may reflect subcellular targeting of LEA proteins in order to protect critical cellular components from desiccation-induced damage. For example, it is reasonable to expect that maintaining the integrity of mitochondria in the dry state would be essential, especially when one considers the potential release of pro-apoptotic factors from the intermembrane space, or the disruption in oxidative phosphorylation that might otherwise occur upon rehydration (54). Stabilization of the inner mitochondrial membrane and the enzymes systems of the matrix requires that protective molecules be able to pass through the double membrane system (55). Nuclear encoded proteins bound for the matrix or inner mitochondrial membrane typically contain a targeting presequence that is recognized by the highly conserved import and incorporation machinery of the organelle $(56,57)$. Localization of LEA proteins to both the cytoplasm and subcellular organelles has now been documented in plant and animal species. 
The group 3 LEA protein (PsLEAm) resides in the mitochondrial matrix of seeds and can be induced in leaves of the pea plant Pisum sativum. The 358 amino acid protein is largely comprised of hydrophilic and charged residues typical of LEA proteins, with the exception of a hydrophobic presequence found at the N-terminus. A fusion protein comprised of this leader sequence and green fluorescent protein (GFP) was expressed in pea leaf protoplast. The resulting mitochondrial localization of GFP demonstrated for the first time in plants the existence of a mitochondrial presequence for a LEA protein. In order to identify in which submitochondrial compartment the LEA protein was located, Grelet et al. (2005) used detergents to differentially solubilize mitochondrial marker proteins for the outer membrane, intermembrane space, inner membrane and matrix. Co-solubilization of PsLEAm with fumarase established that the LEA protein resided in the matrix.

The first LEA protein from an animal species reported to be mitochondrial-targeted was the group 3 AfrLEA3m from A. franciscana (42). This group 3 LEA protein is comprised of 307-amino acids (Table 1) and contains a 29 amino acid presequence at the $\mathrm{N}$-terminus. The hydropathy plot reveals AfrLEA3m is very hydrophilic, with the exception of the presequence, which is relatively hydrophobic (Fig. 2B). Menze et al. (42) showed that when a nucleotide construct encoding the AfrLEA3m presequence was ligated to the nucleotide sequence for GFP and transfected into human hepatoma cells, the chimeric protein was expressed and imported into mitochondria (Fig. 3). The mitochondrial network was clearly visualized as containing GFP, as verified by co-localization of Mitotracker red (Fig. 3Ba, Bb, Bc). In contrast, the GFP lacking the AfrLEA3m leader sequence was not targeted to mitochondria and did not co-localize with Mitotracker Red (Fig. 3Aa, Ab, Ac). The results demonstrated that a mitochondrial targeting sequence is an intrinsic component of AfrLEA3m and strongly suggest that AfrLEA3m is 
naturally localized to mitochondria of A. franciscana. It is appropriate to note that the results also highlight the highly conserved nature of the protein import machinery for mitochondria of mammalian and invertebrate cells, and indirectly, of the targeting sequence as well (42).

The LEA proteins from the bdelloid rotifer A. ricciae, ArLEA1A and ArLEA1B, have an hydrophobic 19 -amino acid $\mathrm{N}$-terminal sequence as well as a putative endoplasmic reticulum retention signal (the amino acid sequence ATEL) at the C-terminus. Therefore, both proteins are likely targeted to, or transported through, the endoplasmic reticulum, although this conclusion awaits experimental evidence (51).

In plants, LEA proteins have been documented to be localized in the cytoplasm, nucleus, mitochondrion, chloroplast, endoplasmic reticulum, vacuole, peroxisome, and plasma membrane (23). It is reasonable to expect an expanded subcellular distribution of LEA proteins in desiccation-tolerant animals in the future.

\section{STRUCTURE OF LEA PROTEINS IN HYDRATED AND DRY STATES}

\section{Hydrophilic Nature and Random Coil in Aqueous Solution}

As is clear from earlier comments, a fundamental biochemical feature of LEA proteins

constituting the major classification groups is their strong hydrophilic nature. Indeed, traditional Kyte and Doolittle hydropathy plots show that virtually all stretches of sequence for a given LEA protein fall in the hydrophilic space of such a plot. For example, each deduced amino acid sequence for group 3 LEA proteins from A. franciscana embryos exhibit negative hydrophobicity scores (Fig. 2A,B). As discussed above, the exception is the presequence that targets a protein to a subcellular organelle. These leader sequences are more hydrophobic than the mature/cleaved sequence (e.g., (42, 58); Fig. 2B). In the fully hydrated state, LEA proteins are predominately unstructured with a preponderance of random coil. In aqueous solution, far 
UV circular dichroism (CD) spectroscopy did not detect significant secondary structure motifs for the group 3 LEA protein from the nematode Aphelenchus avenae AavLEA1; fluorescence emission spectroscopy confirmed that the single hydrophobic tryptophan residue of AavLEA1was fully solvent exposed. Indeed LEA proteins are considered members of the broader classification of intrinsically disordered proteins (IDPs) (e.g., (18)). Their hydrophilic nature fosters an accentuated interaction with solvent water, as discussed further below.

\section{Increase in Secondary Structure during Drying}

Of particular relevance to their proposed functions during conditions of dehydration, LEA proteins exhibit the remarkable ability to become more ordered and develop secondary structure as dehydration proceeds. For animal LEA proteins, this phenomenon was first shown by (59) using fourier-transform infrared (FTIR) spectroscopy. FTIR spectroscopy allows the assessment of protein secondary structure in the dry state by using the profile of the amide-I band, which provides information on the relative contributions of $\alpha$-helix, $\beta$-sheet and turn structures (60). AavLEA1 showed gain of structure during dehydration that was fully reversible upon rehydration. This pattern was originally discovered by (60) for a group 3 LEA protein from Typha latifolia pollen. The T. latifolia protein in solution was largely in a random coil conformation, but it was primarily $\alpha$-helical after fast drying. Interestingly, slow drying reversibly led to both $\alpha$-helical and intermolecular extended $\beta$-sheet structures, which suggested the final protein conformation was not predetermined. Increase in secondary structure during drying also has been reported for LEA proteins from groups 1 and group 2 (dehydrins) (61, 62), and for other group 3 proteins and peptides $(63,64)$. 
A recent modeling study by $\mathrm{Li}$ and $\mathrm{He}(65)$ utilized a 66-amino acid fragment of AavLEA1 and documented nicely many of these properties with molecular dynamics simulation. The simulation of $\mathrm{Li}$ and $\mathrm{He}$ (65) used one molecule of the AavLEA1 fragment and various number of water molecules. These ratios mimicked aqueous solutions of the LEA protein at different water contents from 83.5 to $2.4 \mathrm{wt} \%$. As water is removed, the protein assumes a more folded conformation. At $83.5 \%$ water, the LEA protein is fully solvated with water molecules until the water is decreased to $50 \%$. At $50 \%$ water, 422 molecules of water were predicted to interact with each molecule of LEA protein (Fig. 4). In this range between 83.5 to $50.4 \%$, the protein is unstructured. Below this point, water molecules no longer are sufficient to fully solvate the protein. Below about $20 \%$ water (105 water molecules per protein), the protein becomes more dehydrated and begins adopting a significant amount of secondary structure. Alpha-helical structure is apparent, and the formation of hairpin-like structures appears (Fig. 4). At $2.4 \%$ water (10 water molecules per protein), the structure is very similar to that in the complete absence of water (65). These structural changes are observed during dehydration of the native LEA proteins $(59,63)$, and $\mathrm{Li}$ and $\mathrm{He}(65)$ suggest that since these compact, hairpin structures only appear at very low water percentages, the implication is that a functional role for the protein is in the dry state rather than the hydrated state. The formation of various secondary structures (i.e., $\alpha$-helix, random coils, and $\beta$-sheet) as a function of water removal is shown in Figure 5. Secondary structure is predominantly random coil at water contents more than $20 \mathrm{wt}$. $\%$, again matching experimental results with CD and FTIR (e.g., $(59,60,63,64))$. In the dehydrated state the structure is primarily $\alpha$-helix. 


\section{Structural Stability and Intra-protein Hydrogen Bonding Increases during Desiccation}

Consistent with the gain of secondary structure as LEA proteins are dehydrated, the numbers of intra-protein hydrogen bonds are projected to increase and the number of hydrogen bonds present between the protein and water markedly decrease as water is removed (Fig. 6A). Both projected changes occur primarily at $20 \%$ water and below. Estimates of overall protein stability show that the LEA protein is much more stable at low water percentages, as judged by RMSD (root-mean-square deviation of all atoms on the protein backbone) and MDTF (mean dihedral transition frequency of all amino acids in the protein) (Fig. 6B). The smaller the two parameters, the more stable is the structure of the protein. RMSD and MDTF change dramatically below $20 \%$ water and suggest a strongly stabilized structure at 5 <wt. \%. Li and He (65) suggest that the structural flexibility of the LEA protein in the aqueous condition, versus the compact, folded 3-D shape when water is limiting to macromolecular hydration, may contribute to the respective chaperone and 'molecular shield' functions that have been proposed, and to various degrees supported, by experimentation (discussed below).

\section{PHYSIOLOGICAL ROLES OF LEA PROTEINS WITH AND WITHOUT SUGARS}

Animals with natural tolerance to desiccation often accumulate low molecular weight organic solutes (e.g., trehalose; sucrose quite common in plants) along with protective macromolecules like LEA proteins. Certainly such dual protection with protein and sugar is not always the case, as exemplified by bdelloid rotifers that do not accumulate protective sugars ( 41 , 66). Nevertheless, synthesis of trehalose is well established as one event occurring during acquisition of desiccation tolerance in nematodes $(67,68)$ and other organisms $(69)$. Crowe and colleagues $(67,70)$ reported the compelling observation that unless sufficient time is provided 
for A. avenae to convert glycogen to trehalose prior to desiccation, the nematode does not survive drying; if conversion to trehalose is accomplished during slow drying, dehydration is survived. Apparently trehalose buildup may not be sufficient by itself for anhydrobiosis (25). As Hoekstra and colleagues (25) emphasized for plant desiccation tolerance, one specific mechanism for protection does not confer tolerance on its own; the interplay of several mechanisms simultaneously is essential.

\section{Protection of Proteins and Organelles}

LEA proteins have the capacity to protect target proteins from inactivation and aggregation during water stress, including both freezing and drying. Protection against freezing damage has been extensively studied for group 2 LEA proteins (for review, see (23)) and has been reported for group 3 members $(71,72)$. Reyes et al. $(73,74)$ have shown that group 2 LEA proteins can protect LDH against both drying and freezing, and because the details of the enzyme inactivation appear different, these LEA proteins may be capable of protecting against multiple forms of structural alteration. Protection against damage during drying is wide-spread among various groups of LEA proteins from plants and animals $(58,72,75,76)$.

While the group 3 LEA protein from an anhydrobiotic nematode A. avenae (AavLEA1) can protect citrate sythase against desiccation-induced aggregation without the requirement for any other desiccation protectant like a sugar $(51,72)$, it also displays a synergistic stabilization in the presence of trehalose. There is precedence for such a synergistic protection of proteins against heat stress and during the facilitation of protein folding by trehalose and non-LEA proteins (77-79). A similar observation has been reported with mammalian cell lines for trehalose and the small stress protein p26 (80). 
Goyal et al. $(72,75)$ have proposed that LEA proteins, at least in some cases, exert their protein anti-aggregation function by behaving as 'molecular shields' during water removal; the concept is that the LEA proteins sterically prevent interactions among partially unfolded proteins which would otherwise form intracellular aggregates. However, because desiccation of globular protein often induces aggregation and denaturation (18), LEA proteins would be ineffective at preserving functionality of target proteins in may cases unless they also serve as chaperones, i.e., simply preventing aggregation would be insufficient. Whether or not LEA proteins also form specific complexes with clients characteristic of chaperones is difficult to experimentally demonstrate during drying as the proteins become forced together (cf. (23)).

AavLEA1, a LEA protein found in nematodes, maintains this anti-aggregation capability in vivo (76). Several human cell lines were developed in which the expression of AavLEA1 could be induced. These cells were then tested for anti-aggregation activity using a model protein, EGFP-HDQ74, which is prone to spontaneous aggregation. When cells were induced to express AavLEA1 immediately after transfection with EGFP-HDQ74, there was significantly less aggregation compared to cells that did not express AavLEA1.

Finally, evidence suggests that trehalose and LEA protein stabilize mitochondria during freezing (42). Mitochondria isolated from A. franciscana embryos contain trehalose inside the matrix naturally, and at least one LEA protein (AfrLEA3m) is targeted to the mitochondrial matrix (see above). When these mitochondria are frozen in a trehalose solution (with trehalose and AfrLEA3m naturally present internally), remarkably high respiratory control ratios (succinate plus rotenone) for frozen/thawed mitochondria were observed compared to control, non-frozen mitochondria. These RCR values are much higher than those reported for mammalian mitochondria frozen/thawed without LEA protein and trehalose present only outside (81). 


\section{Interactions with Membranes}

The first evidence that LEA proteins interact with membranes came from work with COR15a from Arabidopsis thaliana (82). COR15a seems able to protect membranes from undergoing detrimental phase transitions during freezing (82). Although not classified as a LEA protein at the time, COR15a was later identified as a group 3 LEA protein by Wise (52). Membrane interaction has since been shown for many other plant LEA proteins, but the function of these interactions is not always clear (for review see (23)).

Molecular modeling of the amphipathic $\alpha$-helices that form upon dehydration of a LEA protein from pea seed mitochondria (PsLEAm) reveals patterns that resemble class A amphipathic helices of apolipoproteins (63). Nearly all of the negative amino acid residues in PsLEAm form a stripe that is bordered on either side by positive residue stripes. Tolleter et al. (63) suggest this pattern indicates the ability of PsLEAm to interact with phospholipid membranes in the dry state, because PsLEAm only assumes this $\alpha$-helical structure upon desiccation and then is able to integrate into the membrane parallel to its plane (63). Further these authors showed that PsLEAm protects liposomes during drying by preventing membrane fusion events as judged by light scattering. Differential scanning calorimetry also indicated interaction of PsLEAm with liposomes in the dry state.

Although most of the evidence for membrane interaction to date involves LEA proteins from plants, this characteristic has also been reported in animals. Puochkina-Stantcheva et al. (51) used FTIR to show that a LEA protein from a bdelloid rotifer (ArLEA1B) interacts with dried liposomes. ArLEA1B is a group 3 LEA protein, but has atypical characteristics as discussed earlier. Unlike typical group 3 LEA proteins that are unstructured in solution, 
ArLEA1B has an $\alpha$-helical structure and is not able to act as a molecular shield (51). In fact the opposite result is seen. When citrate synthase (CS) is dried in the presence of ArLEA1B there is increased aggregation compared to CS dried alone. However, ArLEA1B was found to interact with dry phospholipid membranes to a greater extent than ArLEA1A and AavLEA1, which are able to protect CS. The presence of ArLEA1B significantly decreases the gel-to-liquid crystalline phase-transition temperature $\left(\mathrm{T}_{\mathrm{m}}\right)$ of dry liposomes $(51)$.

The possibility that individual LEA proteins might have different protective abilities may provide an additional explanation for why there are multiple LEA proteins in a single organism. Multiple LEAs may be required, not only for targeting to different organelles, but also to protect different cellular components (e.g., proteins versus membranes) at a given location in the cell. In the case of ArLEA1A and ArLEA1B, both proteins contain a C-terminal ER retention signal and an N-terminal hydrophobic region indicating that they are targeted to the same region in the cell, but they seem to have very different functions (51).

\section{Stabilization of Sugar Glasses}

The observation that LEA proteins can stabilize vitrified sugar glasses (trehalose, sucrose), as judged by shifts in the glass transition temperature $\left(T_{\mathrm{g}}\right)$, was initially reported for a plant LEA protein by Wolkers et al. (60). Vitrification is generally thought to be one important property for substantial dehydration tolerance (cf., $(69,83))$. As described by Hoekstra et al. (25), a sugar glass is "an amorphous metastable state that resembles a solid, brittle material, but with retention of the disorder and physical properties of a liquid. In a glass state, the rates of molecular diffusion and chemical reactions are greatly reduced." Using air-dried sugar or sugar-protein mixtures, the melting of the glasses during heating of the sample was monitored with FTIR by 
observing the position of $\mathrm{OH}$-stretching vibration of the sugar, and $T_{\mathrm{g}}$ values were estimated from frequency versus temperature plots. Compared to $T_{\mathrm{g}}$ for pure sucrose $\left(60^{\circ} \mathrm{C}\right)$, addition of $0.5 \mathrm{mg}$ LEA protein $/ \mathrm{mg}$ sugar raised the $T_{\mathrm{g}}$ to $69^{\circ} \mathrm{C}$ and further to $79^{\circ} \mathrm{C}$ with $0.8 \mathrm{mg}$ protein $/ \mathrm{mg}$ sucrose. High $T_{\mathrm{g}}$ values that are well above ambient temperature are considered physiologically beneficial for an organism, so that the vitrified state will be preserved (i.e., no melting of the sugar glasses will occur) as the environmental temperature increases. It should be noted, however, that the ability of LEA protein to increase the $T_{\mathrm{g}}$ of sugar glasses is not unique, but is also seen for example with poly-L-lysine (84) and hydroxyethyl starch (85).

More recently, a similar impact on $T_{\mathrm{g}}$ has been documented for model synthetic peptides composed of two or four 11-mer motifs of group 3 LEA proteins from insects, nematodes, and plants (64). Thus, each peptide contained 22 or 44 amino acid residues. A control peptide (identical amino acid composition, but randomized sequence) was used for comparison. Mixtures of trehalose and experimental LEA-like peptides exhibited a $7^{\circ} \mathrm{C}$ increase in $T_{\mathrm{g}}$ in peptide-trehalose mixtures compared mixtures using the control peptide. Unfortunately, a direct experimental comparison to pure trehalose was not possible due to a lower water content in the pure trehalose samples versus the peptide mixtures; the presence of even small amounts of water after drying lowers the $T_{\mathrm{g}}$ of sugar mixtures (cf., (86)). In addition, a larger shift toward lower wavenumbers was seen with the experimental peptide mixtures versus control peptide mixtures, which indicates that the hydrogen bonding network in the glassy state was strengthened with the LEA-like peptide compared to the control peptide (64). The work of Wolkers et al (60) and Shimizu et al. (64) support the general concept that sugar glasses are stabilized by the presence of LEA proteins (e.g.,(59)). A glass transition temperature elevated above that of a pure sugar as reported by Wolkers et al. (60) could be of physiological importance when environmental 
temperatures rise and/or cellular water contents increase in desiccated animals. In the future it would be helpful to relate the ratios of sugar:LEA protein used for in vitro studies to those existing in vivo in cells, in order to support the physiological relevance of these findings.

It is appropriate to note that the synthetic peptides used by Shimizu et al. (64) themselves vitrify with a high glass transition temperature $\left(>100^{\circ} \mathrm{C}\right)$; the control (randomized) peptide also exhibited a fairly high glass transition temperature, but approximately $18^{\circ} \mathrm{C}$ lower than experimental peptides. Shimizu et al. (64) suggested that the dried LEA proteins alone should act as a good desiccation protectants, but such a possibility would need to be verified with native LEA proteins.

\section{Hydration Buffers and Ion sequestration}

Another function sometimes suggested for LEA proteins is to serve as a 'hydration buffer' (e.g., (62, 87-89)). The general concept is that unstructured hydrophilic proteins bind greater numbers of water molecules in their hydration shells than a typical globular protein. Bokor et al. (90) estimated with NMR that several intrinsically unstructured proteins (including Arabidpsis thaliana ERD10, a group 2 LEA) bound 20-50\% more water compared to bovine serum albumin. Additional direct measurements of the hydration water for LEA proteins are needed with various NMR approaches and thermodynamic-linkage studies using osmotic stress (91-93). Thus LEA proteins could theoretically retard water loss during dehydration, but does this water binding represent a significant fraction of the total water content in a cell?

The highest concentration for a LEA protein (D-113) in cotton seed approaches $4 \%$ of the total cytosolic protein (88), which is estimated by these authors to represent prior to seed desiccation a LEA concentration in the aqueous phase of cells of $283 \mu \mathrm{M}$, or by our calculations 
about $2.11 \times 10^{8}$ LEA molecules in a $15 \mu \mathrm{m}$ diameter cell with $70 \%$ water content. Using the water binding capacity modeled for a 66-amino acid fragment of the group 3 nematode LEA protein (65) and adjusting for differences in molecular mass, the plant LEA protein could bind around 4140 water molecules per LEA molecule, or 8.74 X $10^{11}$ water molecules bound per cell. Based on the calculated cellular water volume, there would be $4.14 \times 10^{13}$ water molecules per cell. Thus, dividing $8.74 \times 10^{11}$ water molecules bound to D-113 by $4.14 \times 10^{13}$ water molecules per cell suggests that roughly $2 \%$ of total cellular water could be organized by this LEA protein. A second LEA protein (D-7) is expressed in cotton seed that represents $2.6 \%$ of cytosolic protein, which in combination with D-113, could raise the organized water attributable to LEA proteins in cotton seed to over $3 \%$. Nevertheless, the water loss kinetics of only $2-3 \%$ of cell water would be influenced by LEA-specific binding. It seems unlikely that release of this small water fraction during desiccation would be of significant biological advantage, particularly when one considers the many different drying regimes and rates experienced in nature, and the restricted range of water content across which the release would occur (cf. Figs. 4-6).

There are no direct measurements of changes in the kinetics of cellular water loss attributable to the presence of LEA proteins to our knowledge. Across days of development within the seed capsule of intact Arabidopsis thaliana, mutant seeds deficient in expression of ATEM6 (group 1 LEA protein) reached a dehydrated state earlier than wild-type seeds based on morphological evidence (94). However, additional developmental characteristics also appeared to be accelerated in the mutant, so conclusions about absolute differences in water loss rate between mutant and control seeds could benefit from measurement of water kinetics in isolated seeds. For animals, other strategies for slowing the rate of water loss would likely be more quantitatively significant, like anterior-posterior contraction in tardigrades (i.e., formation of the 
"tun" or tonnchenstadien, (95-98) coiling in nematodes (e.g. $(99,100))$, morphological changes in cuticular lipids (the 'permeability slump,' $(101,102))$, and alterations in the egg envelope and perivitelline space that reduced water permeability in diapause fish embryos (103).

Another function often proposed for LEA proteins, due primarily to their hydrophilic/charged nature, is ion sequestration. As cells dehydrate, the overall concentrations in inorganic ions in the cell rise and potentially disrupt enzyme function (cf. (104)). However, if one considers that an animal cell contains $130-150 \mathrm{mM}$ potassium ion (in addition to the anion load) and that levels would increase during dehydration, then it is unlikely that general ion binding by LEA proteins would significantly retard the increase in free ions during dehydration. Even though the number of amino acid residues with ion chelating function is high and the percentage of total cell protein represented by LEA proteins is often substantial, the chelation sites would be minor relative to total free ions. Further, when LEA proteins release their hydration water during desiccation (Fig. 4), the ions bound to the proteins would typically follow suite and also be released thereby voiding any benefit, unless there are highly specific binding sites for ions like $\mathrm{Ca}^{2+}$ (see below). Thus in our view, general ion sequestration would be transient and inconsequential during cell desiccation.

There may be a more physiologically relevant impact of ion sequestration for divalent ions including calcium and metal ions like $\mathrm{Fe}^{3+}, \mathrm{Cu}^{2+}, \mathrm{Zn}^{2+}$ when one considers their nanomolar concentrations in cells. While these binding activities have not been studied for LEA proteins of animals, there are data supporting specific $\mathrm{Ca}^{2+}$ binding sites for plant homologues. Furthermore, there are reports that group 2 (dehydrins) proteins show antioxidant properties, indirectly by sequestering metal ions and directly by scavenging reactive oxygen species (for review see (23)). 


\section{SUMMARY REMARKS AND FUTURE ISSUES}

Understanding the mechanisms present in organisms whose evolutionary history has provided the capacity for natural tolerance to drying and freezing will inform us about fundamental ways by which water limitation can be survived by cells and tissues. The roles of LEA proteins in this context are only beginning to emerge decades after their discovery. More in vivo evidence is needed to support the important inferences made from many excellent in vitro studies.

Among the key biological issues still requiring explanation is the evolutionary origin of these proteins, once thought to exist only in land plants. Discoveries of LEA expression in bacteria, fungi, and multiple animal phyla highlight the need to resolve whether the widespread distribution arises from multiple independent origins versus a primitive ancestral origin coupled to subsequent loss of expression in numerous lineages. The consistent expression of LEA proteins under conditions of water stress in animals and other organisms supports their role in conferring desiccation tolerance, but definitive mechanisms for this presumed function are incomplete (cf. (23)). For example, do LEA proteins confer protection to macromolecules by acting as chaperones, molecular shields or both? Perhaps their action depends on the nature of the specific perturbation involved or if the LEA proteins are working in concert with sugars or other protective solutes. More quantitative measurements of the hydration water of LEA proteins and direct measurements of differential rates of water loss in the presence and absence of LEA proteins will help to clarify whether or not the concept of hydration buffers is realistic.

More information on the subcellular compartmentation of LEA proteins, particularly in animal cells, is required; plant studies are much further ahead in this regard. Quantitative measurements of protein expression levels cells and subcellular compartments in animals would 
help guide the design of in vitro stabilization studies that more closely reflect physiologicallyrelevant ratios of protein to sugar. Such information would be equally important during ectopic expression of LEA proteins in cells for the purpose of conferring desiccation tolerance for applied, biomedical purposes (cf. (55)).

\section{SUMMARY POINTS}

1. Exciting studies now show that LEA proteins are a component in the arsenal of defense mechanisms utilized by many animals that survive severe water stress. Suggested roles of LEA proteins in animals include: protection of proteins through chaperone activity and/or molecular shielding, interaction with and stabilization of phospholipid membranes, and reinforcement of vitrified sugar glasses.

2. Most LEA proteins are highly hydrophilic and intrinsically unstructured in aqueous solution. One extraordinary feature of LEA proteins is their ability to increase secondary structure (predominantly $\alpha$-helix) during drying. This feature suggests important functional differences

for LEA proteins in the dried state. As folding of LEA proteins occurs during water removal, the number of intra-protein hydrogen bonds increase and those between the protein and solvent decrease. Estimates of overall protein stability show that LEA proteins are more stable at low water percentages and display greater structural flexibility in aqueous condition.

3. While LEA proteins themselves possess the ability to protect other macromolecules and biological structures, they are also known to act synergistically with non-reducing disaccharides (e.g., trehalose and sucrose) for this purpose. For example, in vitro stabilization of enzyme activity by LEA proteins during drying is strongly enhanced by trehalose. Furthermore, direct 
evidence shows that LEA proteins increase the glass transition temperature $\left(T_{\mathrm{g}}\right)$ of sugars. Higher $T_{\mathrm{g}}$ values may be physiologically important to dehydrated organisms, because the vitrified state will be preserved at higher environmental temperatures.

4. There are many organisms that express multiple isoforms of LEA proteins. The occurrence of more than one type of LEA protein in a single organism suggests multiple subcellular locations and the ability to perform divergent functions. For example, a mitochondrial-targeted LEA protein has been documented in a crustacean, and two similar LEA proteins from the same nematode species have been shown to perform surprisingly different functions.

\section{DISCLOSURE STATEMENT}

The authors are not aware of any biases that might be perceived as affecting the objectivity of this review.

\section{ACKNOWLEDGMENTS}

We thank the National Science Foundation (grant IOS-0920254 to S.C.H. and M.A.M.), the National Institutes of Health (grant 2 RO1 DK046270-14A1 to M.T. and S.C.H.) and the William Wright Family Foundation (donation to S.C.H.) for generous support. Helpful discussions with Dr. Vince LiCata are gratefully acknowledged. 


\section{LITERATURE CITED}

1. Yancey PH. 2005. Organic osmolytes as compatible, metabolic and counteracting cytoprotectants in high osmolarity and other stresses. J Exp Biol 208: 2819-30

2. Yancey PH, Clark ME, Hand SC, Bowlus RD, Somero GN. 1982. Living with water stress: evolution of osmolyte systems. Science 217: 1214-22

3. Bolen DW. 2001. Protein stabilization by naturally occurring osmolytes. Methods Mol Biol 168: 17-36

4. Lin TY, Timasheff SN. 1994. Why do some organisms use a urea-methylamine mixture as osmolyte? Thermodynamic compensation of urea and trimethylamine N-oxide interactions with protein. Biochemistry 33: 12695-701

5. Xie G, Timasheff SN. 1997. The thermodynamic mechanism of protein stabilization by trehalose. Biophys Chem 64: 25-43

6. Timasheff SN. 2002. Protein hydration, thermodynamic binding, and preferential hydration. Biochemistry 41: 13473-82

7. Feder ME, Hofmann GE. 1999. Heat-shock proteins, molecular chaperones, and the stress response: Evolutionary and ecological physiology. Annual Review of Physiology 61: 243-82

8. Clegg JS. 2005. Desiccation tolerance in encysted embryos of the animal extremophile, Artemia. Integr Comp Biol 45: 714-24

9. Clegg JS, Jackson SA, Warner AH. 1994. Extensive intracellular translocations of a major protein accompany anoxia in embryos of Artemia franciscana. Exp Cell Res 212: 77-83

10. Liang P, Amons R, Clegg JS, MacRae TH. 1997. Molecular characterization of a small heat shock/alpha-crystallin protein in encysted Artemia embryos. J Biol Chem 272: 19051-8

11. Liang P, Amons R, Macrae TH, Clegg JS. 1997. Purification, structure and in vitro molecularchaperone activity of Artemia p26, a small heat-shock/alpha-crystallin protein. Eur J Biochem 243: 225-32

12. Qiu Z, Macrae TH. 2008. ArHsp22, a developmentally regulated small heat shock protein produced in diapause-destined Artemia embryos, is stress inducible in adults. FEBS J 275: 355666

13. Qiu Z, Macrae TH. 2008. ArHsp21, a developmentally regulated small heat-shock protein synthesized in diapausing embryos of Artemia franciscana. Biochem J 411: 605-11

14. Willsie JK, Clegg JS. 2001. Nuclear p26, a small heat shock/alpha-crystallin protein, and its relationship to stress resistance in Artemia franciscana embryos. J Exp Biol 204: 2339-50

15. Parsell DA, Lindquist S. 1993. The function of heat-shock proteins in stress tolerance: degradation and reactivation of damaged proteins. Annu Rev Genet 27: 437-96

16. Menze MA, Hand SC. 2009. How do animal mitochondria tolerate water stress? Commun Integr Biol 2: 428-30

17. Browne JA, Dolan KM, Tyson T, Goyal K, Tunnacliffe A, Burnell AM. 2004. Dehydrationspecific induction of hydrophilic protein genes in the anhydrobiotic nematode Aphelenchus avenae. Eukaryotic Cell 3: 966-75

18. Tompa P, Kovacs D. 2010. Intrinsically disordered chaperones in plants and animals. Biochem Cell Biol 88: 167-74

19. Galau GA, Hughes DW, Dure L. 1986. Abscisic-Acid Induction of Cloned Cotton Late Embryogenesis-Abundant (Lea) Messenger-Rnas. Plant Molecular Biology 7: 155-70

20. Dure L, Greenway SC, Galau GA. 1981. Developmental Biochemistry of Cottonseed Embryogenesis and Germination - Changing Messenger Ribonucleic-Acid Populations as Shown by Invitro and Invivo Protein-Synthesis .14. Biochemistry 20: 4162-8

21. Bartels D. 2005. Desiccation tolerance studied in the resurrection plant Craterostigma plantagineum. Integr Comp Biol 45: 696-701

22. Cumming AC. 1999. LEA proteins. In Seed proteins, ed. P Shewry, R Casey, pp. 753-80. Boston: Kluwer Academic Publishers 
23. Tunnacliffe A, Wise MJ. 2007. The continuing conundrum of the LEA proteins. Naturwissenschaften 94: 791-812

24. Shih M-D, Hoekstra FA, Hsing Y-IC. 2008. Late embryogenesis abundant proteins. Advances in Botanical Research 48: 211-55

25. Hoekstra FA, Golovina EA, Buitink J. 2001. Mechanisms of plant desiccation tolerance. Trends Plant Sci 6: 431-8

26. Dure L. 2001. Occurrence of a repeating 11-mer amino acid sequence motif in diverse organisms. Protein and Peptide Letters 8: 115-22

27. Stacy RAP, Aalen RB. 1998. Identification of sequence homology between the internal hydrophilic repeated motifs of Group 1 late-embryogenesis-abundant proteins in plants and hydrophilic repeats of the general stress protein GsiB of Bacillus subtilis. Planta 206: 476-8

28. Battista JR, Park MJ, McLemore AE. 2001. Inactivation of two homologues of proteins presumed to be involved in the desiccation tolerance of plants sensitizes Deinococcus radiodurans R1 to desiccation. Cryobiology 43: 133-9

29. Close TJ, Lammers PJ. 1993. An osmotic stress protein of cyanobacteria is immunologically related to plant dehydrins. Plant Physiol 101: 773-9

30. Eichinger L, Pachebat JA, Glockner G, Rajandream MA, Sucgang R, et al. 2005. The genome of the social amoeba Dictyostelium discoideum. Nature 435: 43-57

31. Abba S, Ghignone S, Bonfante P. 2006. A dehydration-inducible gene in the truffle Tuber borchii identifies a novel group of dehydrins. BMC Genomics 7: 39

32. Katinka MD, Duprat S, Cornillot E, Metenier G, Thomarat F, et al. 2001. Genome sequence and gene compaction of the eukaryote parasite Encephalitozoon cuniculi. Nature 414: 450-3

33. Sales K, Brandt W, Rumbak E, Lindsey G. 2000. The LEA-like protein HSP 12 in Saccharomyces cerevisiae has a plasma membrane location and protects membranes against desiccation and ethanol-induced stress. Biochim Biophys Acta 1463: 267-78

34. Browne J, Tunnacliffe A, Burnell A. 2002. Anhydrobiosis: plant desiccation gene found in a nematode. Nature 416: 38

35. Tyson T, Reardon W, Browne JA, Burnell AM. 2007. Gene induction by desiccation stress in the entomopathogenic nematode Steinernema carpocapsae reveals parallels with drought tolerance mechanisms in plants. Int J Parasitol 37: 763-76

36. Gal TZ, Glazer I, Koltai H. 2003. Differential gene expression during desiccation stress in the insect-killing nematode Steinernema feltiae IS-6. J Parasitol 89: 761-6

37. Haegeman A, Jacob J, Vanholme B, Kyndt T, Mitreva M, Gheysen G. 2009. Expressed sequence tags of the peanut pod nematode Ditylenchus africanus: the first transcriptome analysis of an Anguinid nematode. Mol Biochem Parasitol 167: 32-40

38. Gal TZ, Glazer I, Koltai H. 2004. An LEA group 3 family member is involved in survival of C. elegans during exposure to stress. FEBS Lett 577: 21-6

39. Denekamp NY, Reinhardt R, Kube M, Lubzens E. Late embryogenesis abundant (LEA) proteins in nondesiccated, encysted, and diapausing embryos of rotifers. Biol Reprod 82: 714-24

40. Denekamp NY, Thorne MA, Clark MS, Kube M, Reinhardt R, Lubzens E. 2009. Discovering genes associated with dormancy in the monogonont rotifer Brachionus plicatilis. BMC Genomics 10: 108

41. Tunnacliffe A, Lapinski J, McGee B. 2005. A putative LEA protein, but no trehalose, is present in anhydrobiotic bdelloid rotifers. Hydrobiologia 546: 315-21

42. Menze MA, Boswell L, Toner M, Hand SC. 2009. Occurrence of Mitochondria-targeted Late Embryogenesis Abundant (LEA) Gene in Animals Increases Organelle Resistance to Water Stress. J Biol Chem 284: 10714-9

43. Sharon MA, Kozarova A, Clegg JS, Vacratsis PO, Warner AH. 2009. Characterization of a group 1 late embryogenesis abundant protein in encysted embryos of the brine shrimp Artemia franciscana. Biochem Cell Biol 87: 415-30 
44. Hand SC, Jones D, Menze MA, Witt TL. 2007. Life without water: expression of plant LEA genes by an anhydrobiotic arthropod. J Exp Zool Part A Ecol Genet Physiol 307: 62-6

45. Chen WH, Ge X, Wang W, Yu J, Hu S. 2009. A gene catalogue for post-diapause development of an anhydrobiotic arthropod Artemia franciscana. BMC Genomics 10: 52

46. Bahrndorff S, Tunnacliffe A, Wise MJ, McGee B, Holmstrup M, Loeschcke V. 2009.

Bioinformatics and protein expression analyses implicate LEA proteins in the drought response of Collembola. J Insect Physiol 55: 210-7

47. Clark MS, Thorne MA, Purac J, Grubor-Lajsic G, Kube M, et al. 2007. Surviving extreme polar winters by desiccation: clues from Arctic springtail (Onychiurus arcticus) EST libraries. BMC Genomics 8: 475

48. Kikawada T, Nakahara Y, Kanamori Y, Iwata K, Watanabe M, et al. 2006. Dehydration-induced expression of LEA proteins in an anhydrobiotic chironomid. Biochem Biophys Res Commun 348: 56-61

49. Forster F, Liang C, Shkumatov A, Beisser D, Engelmann JC, et al. 2009. Tardigrade workbench: comparing stress-related proteins, sequence-similar and functional protein clusters as well as RNA elements in tardigrades. BMC Genomics 10: 469

50. Wise MJ, Tunnacliffe A. 2004. POPP the question: what do LEA proteins do? Trends Plant Sci 9: 13-7

51. Pouchkina-Stantcheva NN, McGee BM, Boschetti C, Tolleter D, Chakrabortee S, et al. 2007. Functional divergence of former alleles in an ancient asexual invertebrate. Science 318: 268-71

52. Wise MJ. 2003. LEAping to conclusions: a computational reanalysis of late embryogenesis abundant proteins and their possible roles. BMC Bioinformatics 4: 52-71

53. Solomon A, Salomon R, Paperna I, Glazer I. 2000. Desiccation stress of entomopathogenic nematodes induces the accumulation of a novel heat-stable protein. Parasitology 121 ( Pt 4): 40916

54. Hand SC, Menze MA. 2008. Mitochondria in energy-limited states: mechanisms that blunt the signaling of cell death. J Exp Biol 211: 1829-40

55. Hand SC, Hagedorn M. 2008. New approaches for cell and animal preservation: Lessons from aquatic organisms. In Oceans and Human Health: Risks and Remedies from the Seas, ed. PJ Walsh, LE Smith, LE Fleming, H Solo-Gabriele, WH Gerwick, pp. 611-29: Academic Press

56. Neupert W, Herrmann JM. 2007. Translocation of proteins into mitochondria. Annu Rev Biochem 76: 723-49

57. Bolender N, Sickmann A, Wagner R, Meisinger C, Pfanner N. 2008. Multiple pathways for sorting mitochondrial precursor proteins. EMBO Rep 9: 42-9

58. Grelet J, Benamar A, Teyssier E, Avelange-Macherel MH, Grunwald D, Macherel D. 2005. Identification in pea seed mitochondria of a late-embryogenesis abundant protein able to protect enzymes from drying. Plant Physiol 137: 157-67

59. Goyal K, Tisi L, Basran A, Browne J, Burnell A, et al. 2003. Transition from natively unfolded to folded state induced by desiccation in an anhydrobiotic nematode protein. J Biol Chem 278: 12977-84

60. Wolkers WF, McCready S, Brandt WF, Lindsey GG, Hoekstra FA. 2001. Isolation and characterization of a D-7 LEA protein from pollen that stabilizes glasses in vitro. Biochim Biophys Acta 1544: 196-206

61. Boudet J, Buitink J, Hoekstra FA, Rogniaux H, Larre C, et al. 2006. Comparative analysis of the heat stable proteome of radicles of Medicago truncatula seeds during germination identifies late embryogenesis abundant proteins associated with desiccation tolerance. Plant Physiol 140: 141836

62. Mouillon JM, Gustafsson P, Harryson P. 2006. Structural investigation of disordered stress proteins. Comparison of full-length dehydrins with isolated peptides of their conserved segments. Plant Physiol 141: 638-50 
63. Tolleter D, Jaquinod M, Mangavel C, Passirani C, Saulnier P, et al. 2007. Structure and function of a mitochondrial late embryogenesis abundant protein are revealed by desiccation. Plant Cell 19: $1580-9$

64. Shimizu T, Kanamori Y, Furuki T, Kikawada T, Okuda T, et al. 2010. Desiccation-induced structuralization and glass formation of group 3 late embryogenesis abundant protein model peptides. Biochemistry 49: 1093-104

65. Li D, He X. 2009. Desiccation induced structural alterations in a 66-amino acid fragment of an anhydrobiotic nematode late embryogenesis abundant (LEA) protein. Biomacromolecules 10: 1469-77

66. Tunnacliffe A, Lapinski J. 2003. Resurrecting Van Leeuwenhoek's rotifers: a reappraisal of the role of disaccharides in anhydrobiosis. Philosophical Transactions of the Royal Society of London Series B-Biological Sciences 358: 1755-71

67. Madin KAC, Crowe JH. 1975. Anhydrobiosis in Nematodes - Carbohydrate and LipidMetabolism during Dehydration. Journal of Experimental Zoology 193: 335-42

68. Goyal K, Browne JA, Burnell AM, Tunnacliffe A. 2005. Dehydration-induced tps gene transcripts from an anhydrobiotic nematode contain novel spliced leaders and encode atypical GT-20 family proteins. Biochimie 87: 565-74

69. Crowe JH, Crowe LM, Carpenter JF, Prestrelski SJ, Hoekstra FA, et al. 1997. Anhydrobiosis: Cellular adaptation to extreme dehydration. In Handbook of Physiology, ed. WH Dantzler, pp. 1445-77. Oxford: Oxford University Press

70. Crowe JH, Madin KAC, Loomis SH. 1977. Anhydrobiosis in nematodes: metabolism during resumption of activity. J Exp Zool 201: 57-64

71. Honjoh K, Matsumoto H, Shimizu H, Ooyama K, Tanaka K, et al. 2000. Cryoprotective activities of group 3 late embryogenesis abundant proteins from Chlorella vulgaris $\mathrm{C}-27$. Bioscience Biotechnology and Biochemistry 64: 1656-63

72. Goyal K, Walton LJ, Tunnacliffe A. 2005. LEA proteins prevent protein aggregation due to water stress. Biochem J 388: 151-7

73. Reyes JL, Rodrigo MJ, Colmenero-Flores JM, Gil JV, Garay-Arroyo A, et al. 2005. Hydrophilins from distant organisms can protect enzymatic activities from water limitation effects in vitro. Plant Cell and Environment 28: 709-18

74. Reyes JL, Campos F, Wei H, Arora R, Yang YI, et al. 2008. Functional dissection of Hydrophilins during in vitro freeze protection. Plant Cell and Environment 31: 1781-90

75. Goyal K, Pinelli C, Maslen SL, Rastogi RK, Stephens E, Tunnacliffe A. 2005. Dehydrationregulated processing of late embryogenesis abundant protein in a desiccation-tolerant nematode. Febs Letters 579: 4093-8

76. Chakrabortee S, Boschetti C, Walton LJ, Sarkar S, Rubinsztein DC, Tunnacliffe A. 2007. Hydrophilic protein associated with desiccation tolerance exhibits broad protein stabilization function. Proceedings of the National Academy of Sciences of the United States of America 104: 18073-8

77. Singer MA, Lindquist S. 1998. Multiple effects of trehalose on protein folding in vitro and in vivo. Mol Cell 1: 639-48

78. Singer MA, Lindquist S. 1998. Thermotolerance in Saccharomyces cerevisiae: the Yin and Yang of trehalose. Trends Biotechnol 16: 460-8

79. Viner RI, Clegg JS. 2001. Influence of trehalose on the molecular chaperone activity of p26, a small heat shock/alpha-crystallin protein. Cell Stress Chaperones 6: 126-35

80. Ma X, Jamil K, Macrae TH, Clegg JS, Russell JM, et al. 2005. A small stress protein acts synergistically with trehalose to confer desiccation tolerance on mammalian cells. Cryobiology 51: $15-28$

81. Yamaguchi R, Andreyev A, Murphy AN, Perkins GA, Ellisman MH, Newmeyer DD. 2007. Mitochondria frozen with trehalose retain a number of biological functions and preserve outer membrane integrity. Cell Death Differ 14: 616-24 
82. Steponkus PL, Uemura M, Joseph RA, Gilmour SJ, Thomashow MF. 1998. Mode of action of the COR15a gene on the freezing tolerance of Arabidopsis thaliana. Proceedings of the National Academy of Sciences of the United States of America 95: 14570-5

83. Crowe JH, Carpenter JF, Crowe LM. 1998. The role of vitrification in anhydrobiosis. Annual Review of Physiology 60: 73-103

84. Wolkers WF, van Kilsdonk MG, Hoekstra FA. 1998. Dehydration-induced conformational changes of poly-L-lysine as influenced by drying rate and carbohydrates. Biochim Biophys Acta 1425: $127-36$

85. Crowe JH, Oliver AE, Hoekstra FA, Crowe LM. 1997. Stabilization of dry membranes by mixtures of hydroxyethyl starch and glucose: the role of vitrification. Cryobiology 35: 20-30

86. Chen T, Fowler A, Toner M. 2000. Literature review: supplemented phase diagram of the trehalose-water binary mixture. Cryobiology 40: 277-82

87. Mccubbin WD, Kay CM, Lane BG. 1985. Hydrodynamic and Optical-Properties of the WheatGerm Em Protein. Canadian Journal of Biochemistry and Cell Biology 63: 803-11

88. Roberts JK, Desimone NA, Lingle WL, Dure L. 1993. Cellular Concentrations and Uniformity of Cell-Type Accumulation of 2 Lea Proteins in Cotton Embryos. Plant Cell 5: 769-80

89. Garay-Arroyo A, Colmenero-Flores JM, Garciarrubio A, Covarrubias AA. 2000. Highly hydrophilic proteins in prokaryotes and eukaryotes are common during conditions of water deficit. Journal of Biological Chemistry 275: 5668-74

90. Bokor M, Csizmok V, Kovacs D, Banki P, Friedrich P, et al. 2005. NMR relaxation studies on the hydrate layer of intrinsically unstructured proteins. Biophys $J$ 88: 2030-7

91. Wider G. 1998. Technical aspects of NMR spectroscopy with biological macromolecules and studies of hydration in solution. Progress in Nuclear Magnetic Resonance Spectroscopy 32: 193275

92. LiCata VJ, Allewell NM. 1998. Measuring hydration changes of proteins in solution: Applications of osmotic stress and structure-based calculations. Energetics of Biological Macromolecules, Pt B 295: 42-62

93. LiCata VJ, Allewell NM. 1997. Functionally linked hydration changes in Escherichia coli aspartate transcarbamylase and its catalytic subunit. Biochemistry 36: 10161-7

94. Manfre AJ, Lanni LM, Marcotte WR. 2006. The Arabidopsis group 1 LATE EMBRYOGENESIS ABUNDANT protein ATEM6 is required for normal seed development. Plant Physiology 140: 140-9

95. Baumann H. 1922. Die Anabiose der Tardigraden. Zool Jb Syst 45: 501-56

96. Crowe JH, Newell IM, Thomson WW. 1971. Fine Structure and Chemical Composition of Cuticle of Tardigrade, Macrobiotus-Areolatus Murray. Journal of Microscopy-Oxford 11: 107-\&

97. Walz B. 1979. Morphology of Cells and Cell Organelles in the Anhydrobiotic Tardigrade, Macrobiotus-Hufelandi. Protoplasma 99: 19-30

98. Wright JC. 1989. Desiccation Tolerance and Water-Retentive Mechanisms in Tardigrades. Journal of Experimental Biology 142: 267-92

99. Crowe JH, Madin KA. 1974. Anhydrobiosis in tardigrades and nematodes. Trans Amer Micros Soc 93: 513-24

100. Demeure Y, Freckman DW, Vangundy SD. 1979. Anhydrobiotic Coiling of Nematodes in Soil. Journal of Nematology 11: 189-95

101. Wright JC. 1988. The tardigrade cuticle. I. Fine structure and the distribution of lipids. Tissue \& Cell 20: 745-58

102. Wright JC. 1989. The tardigrade cuticle II. Evidence for a dehydration-dependent permeability barrier in the intracuticle. Tissue \& Cell 21: 263-79

103. Podrabsky JE, Carpenter JF, Hand SC. 2001. Survival of water stress in annual fish embryos: dehydration avoidance and egg envelope amyloid fibers. American Journal of PhysiologyRegulatory Integrative and Comparative Physiology 280: R123-R31 
104. Hand SC. 1992. Water content and metabolic organization in anhydrobiotic aninmals. In Water and Life, ed. GN Somero, CB Osmond, CL Bolis, pp. 104-27. Berlin: Springer-Verlag 
Table 1. Full sequences and selected ESTs for LEA-like proteins from animal species.

\begin{tabular}{|c|c|c|c|c|c|}
\hline Species (Identification) & Acc. number & Length & Group & Hydropathy Score & Evidence, Ref \\
\hline Adineta ricciae (ArLEA1A) & ABU62809 & 421 & LL (3) & -0.460 & Expression, (51) \\
\hline Adineta ricciae (ArLEA1B) & ABU62810 & 376 & LL (3) & -0.465 & Expression, (51) \\
\hline Adineta vaga (lea-1B') & ADD91479 & 354 & LL (3) & -0.626 & None \\
\hline Adineta vaga (lea1-C) & ADD91460 & 231 & LL (3) & -0.694 & None \\
\hline Aphelenchus avenae (Aav-LEA-1) & AAL18843 & 143 & 3 & -1.585 & Expression, $(17,34)$ \\
\hline Aphelenchus avenae (LEA-like 2) & ABQ23232 & 102 & LL (3) & -1.376 & None \\
\hline Aphelenchus avenae (LEA-like 1) & ABQ23233 & 85 & LL (3) & -1.832 & None \\
\hline Artemia franciscana (AfrLEA1) & ACA47267 & 357 & 3 & -1.027 & Expression, (44) \\
\hline Artemia franciscana (AfrLEA2) & ACA47268 & 364 & 3 & -0.884 & Expression, (44) \\
\hline Artemia franciscana (AfrLEA3m) & ACM16586 & 307 & 3 & -1.295 & Expression, (42) \\
\hline Artemia franciscana & ACX81198* & 217 & 1 & -1.257 & None \\
\hline Artemia franciscana (Group 1 LEA) & ABX89317* & 182 & 1 & -1.410 & Expression, (43) \\
\hline Brachionus plicatilis (BpaLEA-1) & ADE05593 & 613 & LL (3) & -1.248 & Expression, $(39,40)$ \\
\hline Brachionus plicatilis (BpaLEA-2) & ADE05594 & 248 & LL (3) & -1.219 & Expression, $(39,40)$ \\
\hline Caenorhabditis briggsae (Cbr-LEA-1) & XP_002637990 & 732 & LL (3) & -1.104 & None \\
\hline Caenorhabditis briggsae & XP_002638006 & 775 & LL (3) & -0.899 & None \\
\hline Caenorhabditis elegans (CeLEA1) & NP_001024042 & 733 & LL (3) & -1.126 & Expression, (38) \\
\hline Caenorhabditis elegans (K08H10.2) & NP_505575 & 497 & LL (3) & -1.054 & None \\
\hline Ditylenchus africanus & FE923587 & (142) EST & LL (3) & -1.422 & None, (37) \\
\hline Ditylenchus africanus & FE923426 & (77) EST & LL (3) & -1.145 & None, (37) \\
\hline Megaphorura arctica & EW755263 & (147) EST & LL (3) & -1.297 & Cross-reactivity, $(46,47)$ \\
\hline Polypedilum vanderplanki (PvLEA1) & BAE92616 & 742 & 3 & -0.643 & Expression, (48) \\
\hline Polypedilum vanderplanki (PvLEA2) & BAE92617 & 180 & 3 & -1.263 & Expression, (48) \\
\hline Polypedilum vanderplanki (PvLEA3) & BAE92618 & 484 & 3 & -0.340 & Expression, (48) \\
\hline Pratylenchus penetrans & BQ627245 & (87) EST & LL (3) & -1.383 & None \\
\hline Steinernema carpocapsae & $\mathrm{ABQ} 23231^{\$}$ & 95 & LL (3) & -1.194 & Expression, (35) \\
\hline Steinernema feltiae (Sf-LEA-1) & AAM81356 & 102 & LL (3) & -1.321 & Expression, $(36,53)$ \\
\hline
\end{tabular}




\section{Figure Legends}

Figure 1. mRNA expression profiles for Afrleal, Afrlea2, and Afrlea3m from A. franciscana embryos. LEA mRNAs are maintained 7-14-fold higher in the two desiccation-tolerant embryonic stages (i.e., diapause and post-diapause) compared to the desiccation-intolerant nauplius larva that served as a control (modified from (44) and (42)).

Figure 2. (A) Hydropathy plots for the deduced LEA proteins AfrLEA1 and AfrLEA2 indicate strong hydrophilicity, as shown by values below zero (modified from (44)). (B) Hydropathy plot for the deduced protein AfrLEA3 also indicates the strong hydrophilic nature of the protein. The more hydrophobic $\mathrm{N}$-terminal region of about 30 amino acids is a result of the mitochondrial targeting sequence (modified from (42)).

Figure 3: Human hepatoma cells (HepG2/C3A) transfected with either an expression vector encoding for a chimeric protein composed of the leader sequence from AfrLEA3m plus GFP (frames Ba-c), or with the vector encoding only GFP (Aa-c). Co-staining with Mitotracker Red highlights the mitochondrial network ( $\mathrm{Ab}, \mathrm{Bb}$; red color). Green and red fluorescence are colocalized in cells transfected with the chimeric protein $(\mathrm{Bc})$, but not in cells transfected with GFP-only (Ac) where GFP remains in the cytoplasm. Mitotracker red fluorescence is not found in the nucleus (Ac, Bc; nucleus blue) (modified after (42)).

Figure 4. Representative conformations of the 66 amino acid fragment of a LEA protein (AavLEA1) from the nematode A. avenae are shown at different water contents. Water 
molecules are shown in the line style and the LEA protein molecule is denoted using the solid ribbon style with $\alpha$-helix in red, $\beta$-sheet in green, and random coil in gray (modified from (65).

Figure 5. Percentages of the three major secondary structures in the LEA protein fragment from the nematode A. avenae as a function of water content. Symbols represent data from a molecular dynamics (MD) simulation, and the lines are B-spline fits to the MD data. Error bars = one standard deviation. Redrawn from (65).

Figure 6. A. Number of intra-protein and protein-water hydrogen bonds as a function of water content. Symbols represent data from a molecular dynamics (MD) simulation, and the lines are B-spline fits to the MD data. Error bars = one standard deviation. B. RMSD (root-mean-square deviation of all atoms on the protein backbone) and MDTF (mean dihedral transition frequency of all amino acids in the protein) as a function of water content. As above, symbols represent data from the molecular dynamics (MD) simulation, and the lines are B-spline fits to the MD data. Error bars = one standard deviations. Redrawn from (65). 
Figure 1

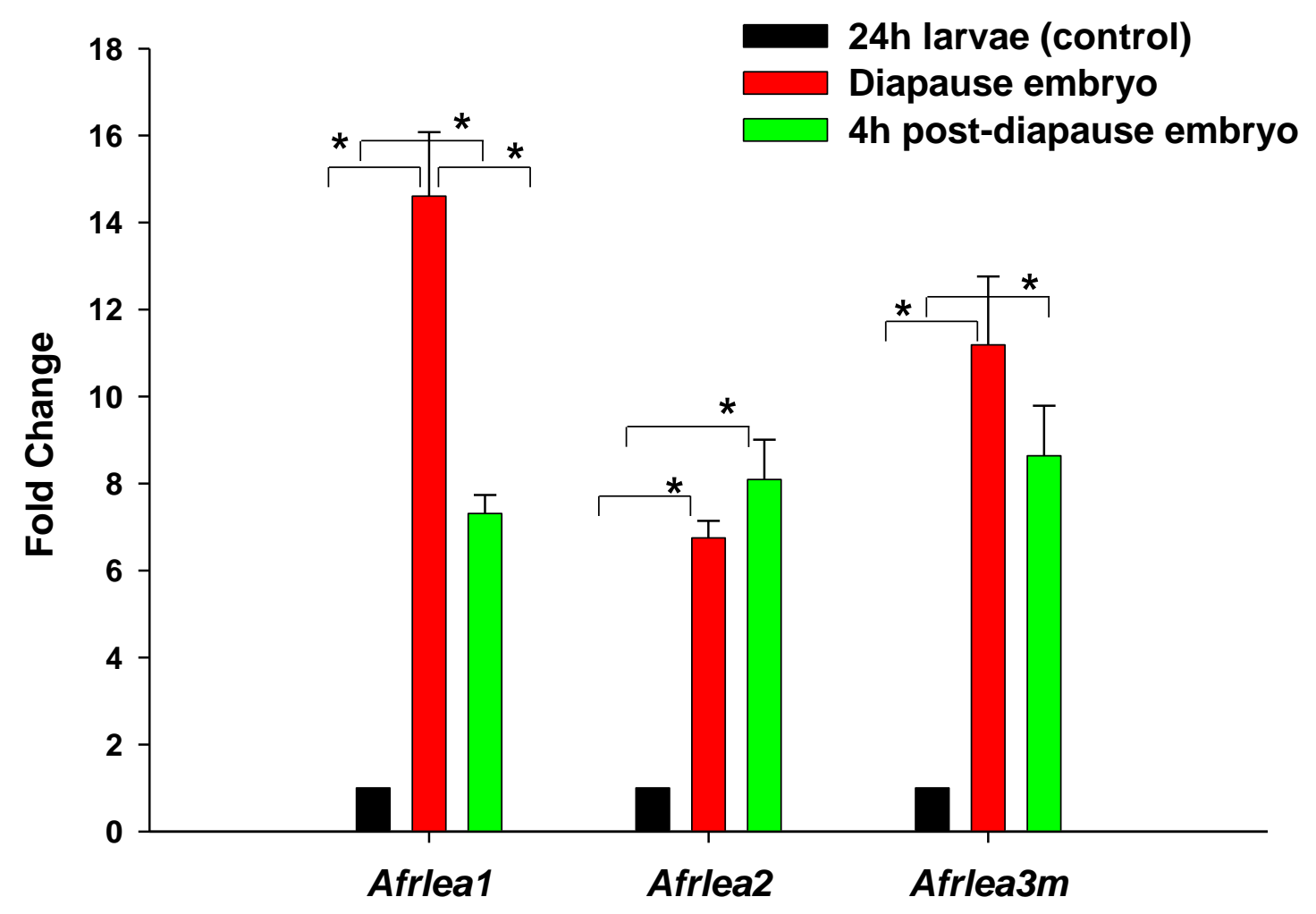


Figure 2
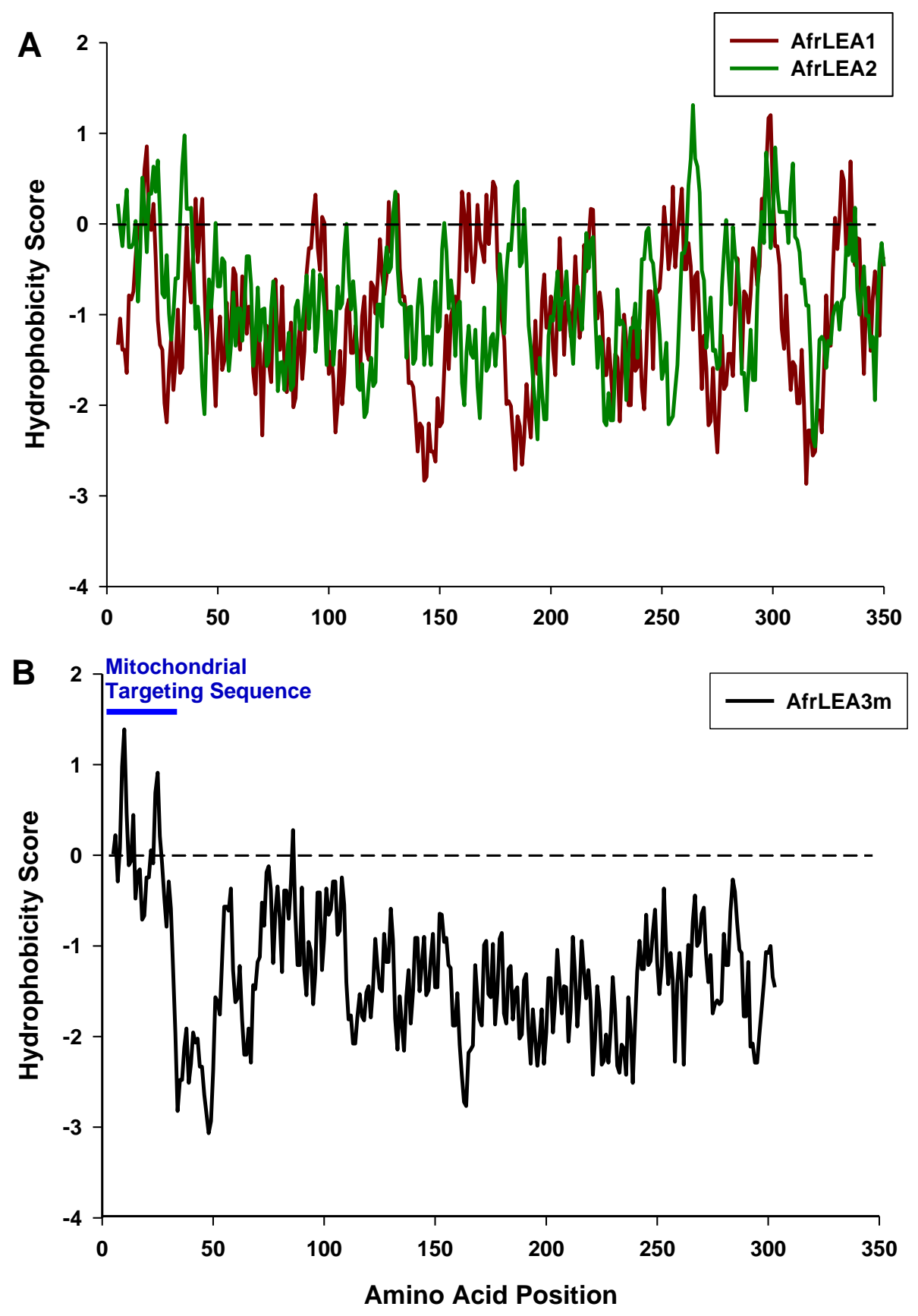
Figure 3.
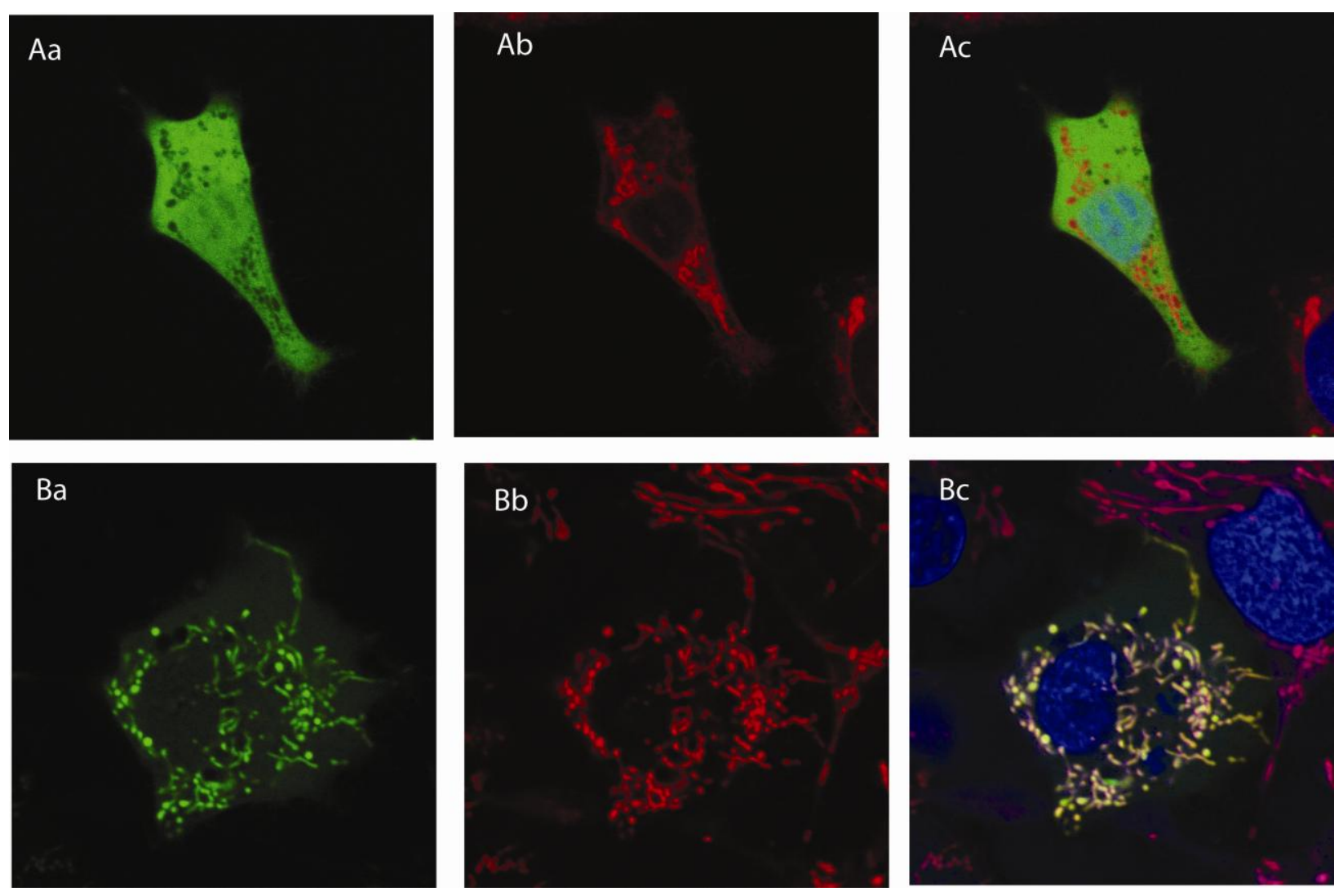
Figure 4

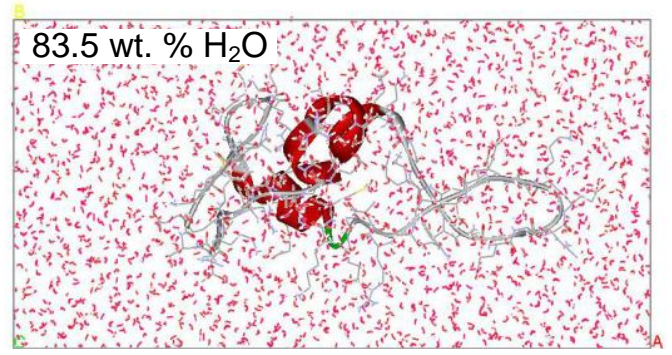

20.2 wt. $\% \mathrm{H}_{2} \mathrm{O}$

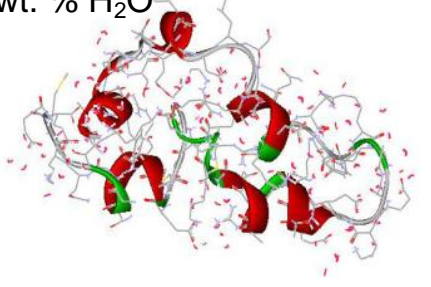

4.8 wt. $\% \mathrm{H}_{2} \mathrm{O}$

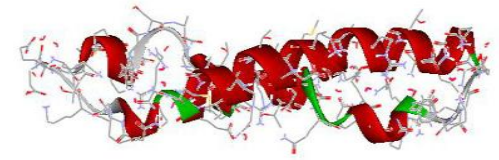

50.4 wt. \%

$\mathrm{H}_{2} \mathrm{O}$

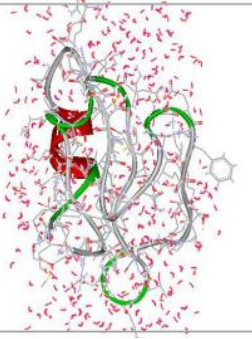

13.2 wt. $\% \mathrm{H}_{2} \mathrm{O}$

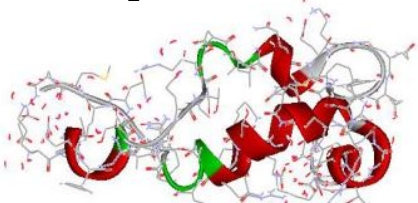

2.4 wt. $\% \mathrm{H}_{2} \mathrm{O}$

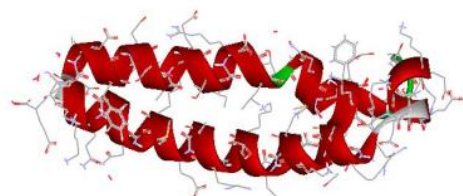


Figure 5

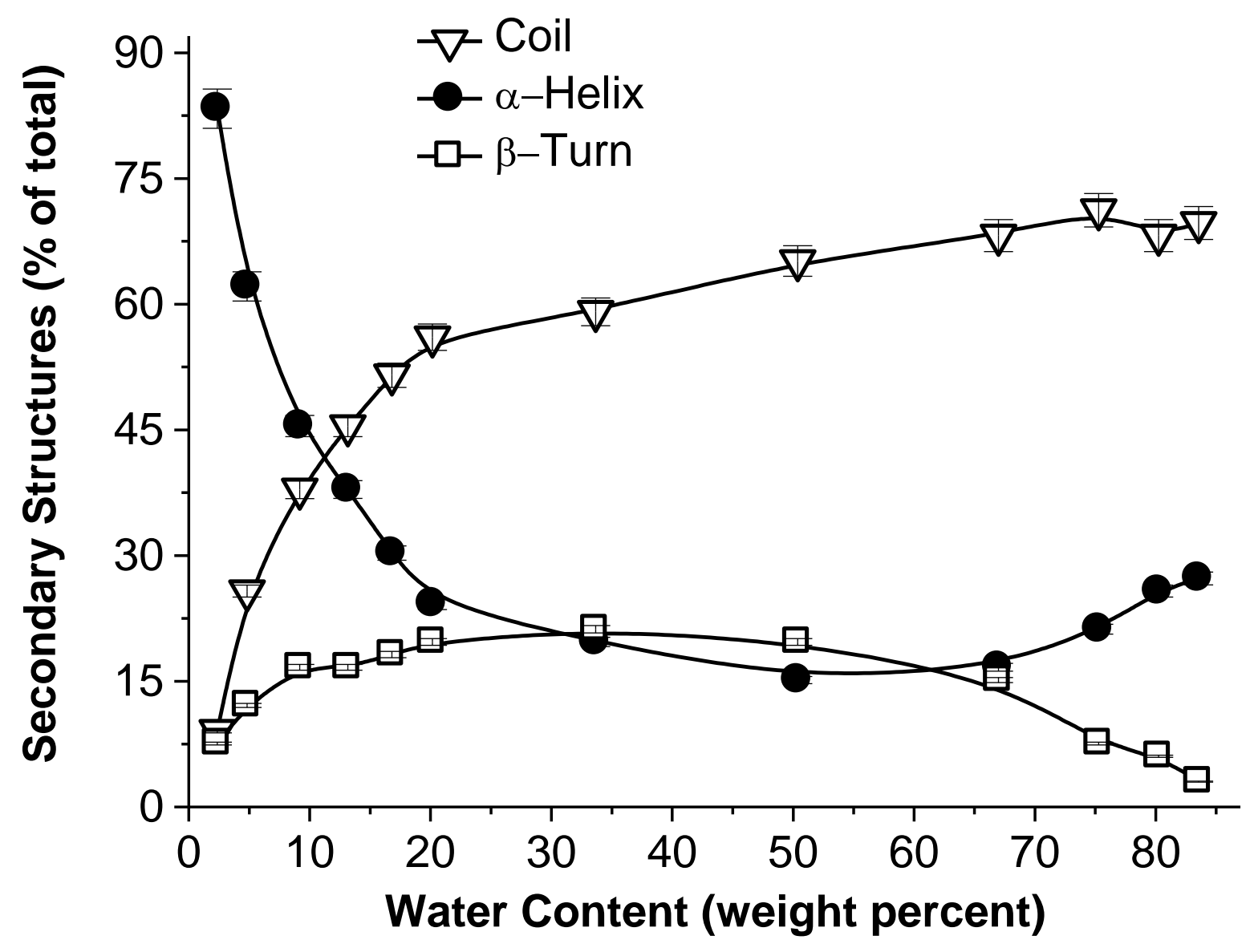


Figure 6
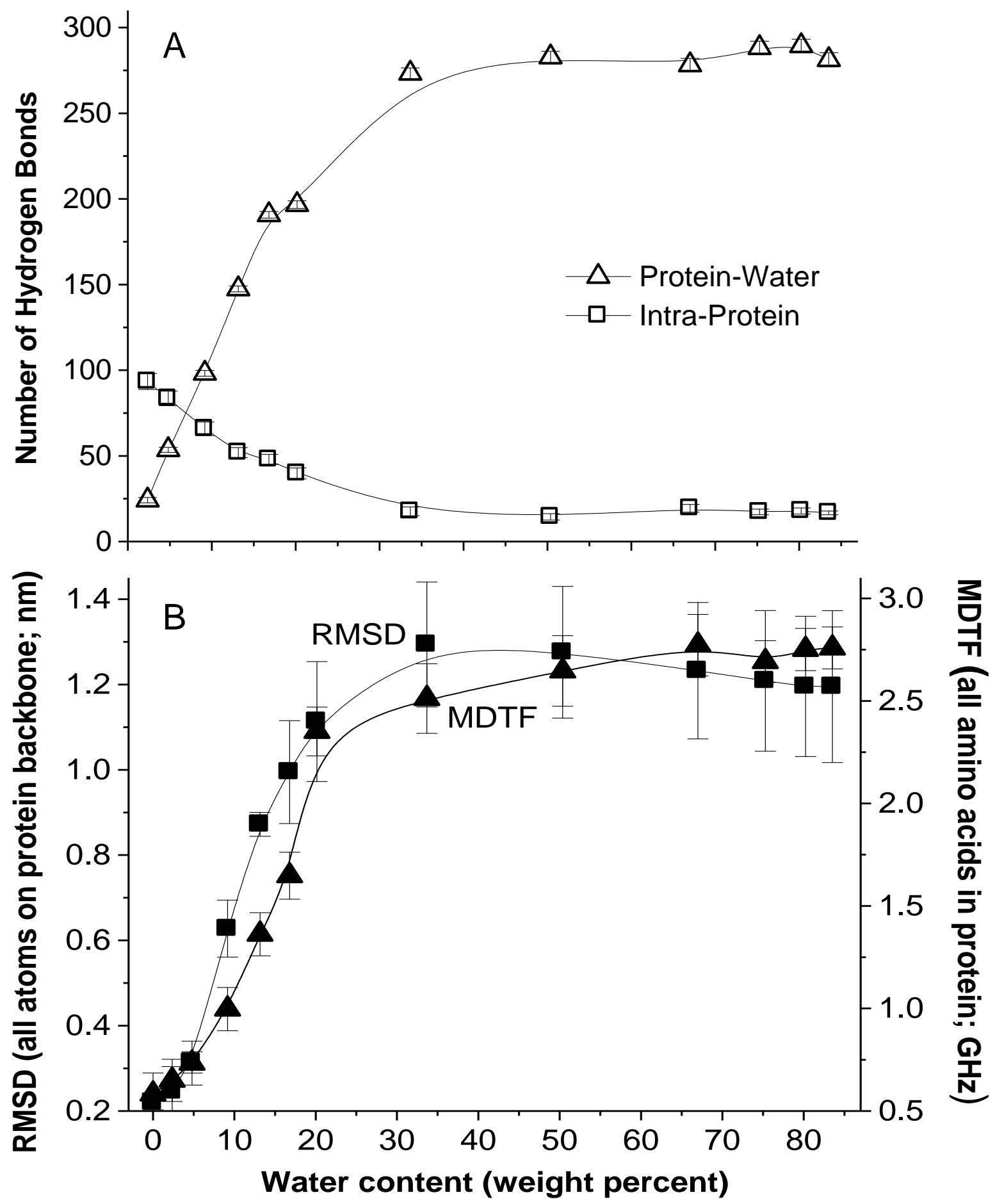
